\title{
A Six Sigma Approach to Internal ALM Models for Solvency II
}

\author{
Vojo Bubevski \\ 21 Gordon Road, Portslade, Brighton BN41 1GL, United Kingdom
}

\begin{abstract}
A Six Sigma method is proposed to improve the investment management process. In addition to conventional stochastic optimisation, simulation and risk management, as a new concept, Six Sigma DMAIC (Define, Measure, Analyse, Improve and Control) is applied by merging DMAIC into portfolio management. The method is applicable to internal models for Solvency II in order to reduce the capital requirements and Value at Risk. By using it, the financial institutions can achieve higher business capabilities and increase their competitive position, which is their ultimate objective.
\end{abstract}

Keywords-investment management; portfolio analysis; asset \& liability management; solvency ii; six sigma dmaic; stochastic optimisation; monte carlo simulation

\section{INTRODUCTION}

Asset \& Liability Management (ALM) has originated from the duration analysis proposed by Macaulay (1938) and Redington (1952). Subsequently, ALM has evolved in a powerful and integrated tool for analysis of assets and liabilities (Bloomsbury 2012).

Solvency II is a European Union (EU) Directive, which was approved by the European Parliament, and came into effect on 1 January 2016. Solvency II regulation is designed to introduce a harmonised insurance regulatory regime across the EU that will protect policyholders and minimise market disruption. The regulation sets stronger requirements for capital adequacy, risk management and disclosure. The regulation provides standard generic models, which necessitate higher capital requirements (GDV 2005; SST 2004). The insurance companies have an option to develop internal models specific to their financial status, thus reducing the capital requirements (Bourdeau 2009; Cruz 2009). Another aspect of Solvency II is Financial Risk Management elaborated by Jorion (2011).

The problem of asset allocation for portfolio optimisation was solved by Mean-Variance method (Markowitz 1952; 1987). Nowadays, stochastic optimisation, which applies Monte Carlo simulation, is used to resolve the optimal portfolio (Glasserman 2004; Ziemba and Vickson 2006). For example, an Carlo Simulation model for Solvency II was presented by Bourdeau (2009). Also, Mitra and Schwaiger (2011) published quantitative ALM internal models for Solvency II. In addition, Adam (2007) published advanced ALM stochastic models for Solvency II using optimisation and simulation methodologies.
Bernstein and Damodaran (1998) elaborated the investment process. They emphasized the importance of the investment process; which is generic regardless of what the investment philosophy, or strategy is applied, or what assets are involved - an asset is an asset is an asset. Also, Maginn et al. (2007) presented and defined Portfolio Management as an ongoing process incorporating the applicable criteria.

According to Bernstein and Damodaran (1998), the investment process comprises the following sub-processes:

1. Understanding the Investor/Client

2. Portfolio Construction including Asset Allocation, Asset Selection; Portfolio Execution.

3. Ongoing Portfolio Management including Performance Evaluation, Financial Risk Management and Portfolio Revision.

Most industries today recognise Six Sigma as a standard means to accomplish process and quality improvements. One of the principal Six Sigma methodologies is Define, Measure, Analyse, Improve, and Control (DMAIC). DMAIC comprises: i) Define: defining the process, objectives and quality goals; ii) Measure: establishing the metrics and measuring the current process performance; iii) Analyze: analysing the measurement results and collected data to determine the root causes of the process variability and risk; iv) Improve: considering alternatives to eliminate the root causes and determining and applying the improvement solution to upgrade the process; and v) Control: continuous monitoring and establishing corrective mechanisms to rectify the deviations and control the process performance in the future (Siviy, Penn and Stoddard 2007).

The financial industry has also used Six Sigma to improve their processes. For example, Six Sigma introductory topics for financial professionals were published by Stamatis (2003). Hayler and Nichols (2006) showed how financial giants such as American Express, Bank of America, and Wachovia have applied Six Sigma, Lean their service-based operations. Also, Tarantino and Cernauskas (2009) provided an operational risk framework by using proven Six Sigma methods.

A practical Six Sigma Portfolio Management method is proposed. Six Sigma DMAIC is systematically used as a tactical framework to improve the investment process, which is a new concept. In addition to conventional techniques, the new concept involves: a) stochastic measurement of portfolio performance by using the Six Sigma process capability metrics considering portfolio's Mean Return, VAR, and Sharpe Ratio; b) continuous monitoring and control of portfolio performance 
on the market by iteratively and recursively applying the DMAIC framework. In the paper, Microsoft ${ }^{\mathrm{TM}}$ Excel ${ }^{\circledR}$, Palisade $^{\mathrm{TM}} @$ RISK ${ }^{\circledR}$ and RISKOptimizer ${ }^{\circledR}$ were used for modeling.

\section{THE METHOD}

\section{A. The Concept}

The Six Sigma portfolio management method has two dimensions: Portfolio Management and Six Sigma DMAIC. Portfolio Management has two phases i) Portfolio Construction; and ii) Ongoing Portfolio Management. Therefore, the method iteratively and recursively applies DMAIC processes into Portfolio Management as follows.

\section{1)Portfolio construction:}

The optimal portfolios should satisfies the investor's requirements: a) DMAIC-Define: Determine Efficient Frontier of initial minimal mean-variance portfolios; b) DMAICMeasure: Measure portfolio performance; c) DMAIC-Analyse: Performance evaluation and Risk attribution of initial portfolios; d) DMAIC-Improve: Based on performance analysis, revise the initial portfolios resulting in Efficient Frontier of revised portfolios; e) DMAIC-Analyse: Select the best technical portfolio (e.g. the portfolio with maximal Sharp Ratio) from Efficient Frontier of revised portfolios and execute it.

\section{2)DMAIC-control ongoing}

Portfolio Management: Performs regular monitoring including: a) measurement (i.e. DMAIC-Measure); b) evaluation and risk attribution (i.e. DMAIC-Analyse); of the executed portfolio's performance; c) DMAIC-Improve: based on the analysis of portfolio's performance, the portfolio is revised according to the changes in the market and the position of the investor. The changed portfolio is then executed.

\section{B. Problem Statement}

Construct and execute an optimal portfolio with expected return in the range $8.8 \%, 9 \% \ldots, 10 \%$ and $10.2 \%$ considering Efficient Frontier. Stochastically calculate and measure the Variance, Standard Deviation, VAR, and Sharpe Ratio. Perform on regular basis portfolio performance measurement, evaluation and attribution and revise the portfolio considering changes in the market and the position of the investor.

\section{Financial Market Data and Calculations}

The Monthly Return (MR) of the four selected assets is available for the period from January 2007 to April 2014. The data January 2007 - October 2013 are used for demonstration and November 2013 - April 2014 are used for verification of the results. The calculations used by the method involve:

1. Compounded Monthly Return $(C M R)$ :

$$
\mathrm{CMR}=\ln (1+\mathrm{MR})
$$

2. Assets fitted distribution is given by $@$ RISK $\mathbb{R}$ functions:

CMR1=RiskLogistic $(0.01,0.05))$

CMR2=RiskLognorm $(1.13,0.08$, Shift(-1.12))

CMR3= RiskWeibull (6.95,0.46, Shift(-0.43))

CMR4= RiskNormal $(0.006,0.047)$

3. Compounded Annual Return (CAR):

$$
\mathrm{CAR}=12 * \mathrm{CMR}
$$

4. Expected Annual Return Mean (EAR-Mean) Excel ${ }^{\circledR}$ :

C EAR-Mean $=$ SumProduct $($ Weights-V, CAR-V)

5. Variance, Standard Deviation and VAR (@RISK®):

$$
\text { Variance }=\text { RiskVariance }(\text { EAR-Mean })
$$

Standard-Deviation $=$ RiskStdDev $($ EAR-Mean $)$

$\mathrm{VAR}=$ RiskPercentile (EAR-Mean,0.005)

6. Sharp Ratio:

$$
\text { Sharpe Ratio }=(\mu-r) / \sigma
$$

Where, $\mu=$ Expected Annual Return Mean (EAR-Mean), $\sigma$ $=$ Standard-Deviation, and $\mathrm{r}=$ Risk Free Rate, which is estimated to be $5.35 \%$.

7. Six Sigma Process metrics involves:

a) Target Parameters: i) Lower Specified Limit (LSL); ii) Target Value (TV); and iii) Upper Specified Limit (USL).

b) Capability: Probability of Non-Compliance (PNC):

$$
\mathrm{PNC}=\text { RiskPNC (EAR-Mean }
$$

\section{RESULTS AND DISCUSSION}

The overall results of all the portfolios on the Efficient Frontier are presented in Table 1. 
TABLE I. THE OVERALL RESULTS

\begin{tabular}{|c|c|c|c|c|}
\hline $\boldsymbol{\mu}$ & $\mathbf{V}$ & $\boldsymbol{\sigma}$ & $\mathbf{V A R}$ & $\mathbf{S R}$ \\
\hline 0.088 & 0.223 & 0.472 & -0.204 & 0.073 \\
\hline 0.088 & 0.174 & 0.417 & -0.036 & 0.083 \\
\hline 0.090 & 0.232 & 0.482 & -0.228 & 0.076 \\
\hline 0.090 & 0.181 & 0.425 & -0.066 & 0.086 \\
\hline 0.092 & 0.247 & 0.497 & -0.283 & 0.077 \\
\hline 0.092 & 0.193 & 0.439 & -0.124 & 0.088 \\
\hline 0.094 & 0.266 & 0.515 & -0.362 & 0.079 \\
\hline 0.094 & 0.217 & 0.466 & -0.212 & 0.087 \\
\hline 0.096 & 0.295 & 0.543 & -0.454 & 0.078 \\
\hline 0.096 & 0.252 & 0.502 & -0.326 & 0.085 \\
\hline 0.098 & 0.332 & 0.576 & -0.537 & 0.077 \\
\hline 0.098 & 0.298 & 0.546 & -0.446 & 0.082 \\
\hline 0.100 & 0.378 & 0.615 & -0.625 & 0.076 \\
\hline 0.100 & 0.348 & 0.590 & -0.565 & 0.079 \\
\hline 0.102 & 0.429 & 0.655 & -0.732 & 0.074 \\
\hline 0.102 & 0.410 & 0.640 & -0.687 & 0.076 \\
\hline
\end{tabular}

The table shows the Mean Return ( $\mu$ ), Variance (V), Standard Deviation $(\sigma)$, VAR, and Sharpe Ratio (SR) of the initial and the associated revised portfolios (shown in Blue).

\section{A. Efficient Frontier of Portfolios}

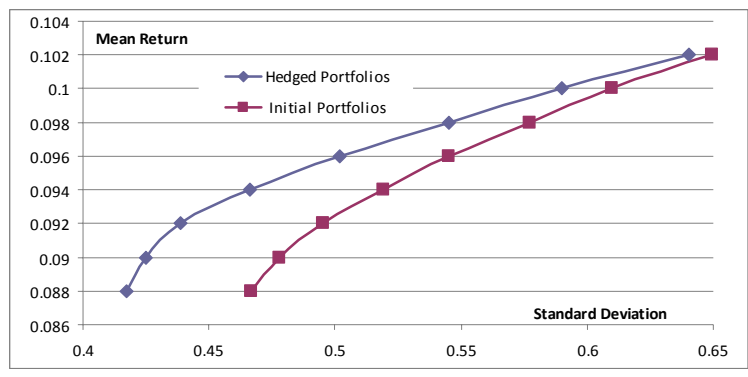

FIGURE I. EFFICIENT FRONTIER OF OPTIMAL PORTFOLIOS

Efficient Frontier of the optimal portfolios is presented in Figure 1. The Efficient Frontier curves show that an increase in expected return of the portfolio causes an increase in the portfolio Standard Deviation. Also, the Efficient Frontiers get flatter as expected. This shows that each additional unit of Standard Deviation allowed, increases the portfolio Mean Return by less and less. To emphasise, the Standard Deviation (i.e. the risk) of revised portfolios for a given return is less than the risk of the original portfolios, thus the revised Efficient Frontier is shifted to the left. Also, Efficient Frontier (i.e. the risk) of revised portfolios asymptotically converges to Efficient Frontier of the original portfolios for higher returns.

\section{B. Portfolios Expected Mean Return versus VAR}

Figure 2 shows the dependency of the expected portfolio returns against VAR. From the graph it is possible to see that an increase in expected return of the portfolio causes an increase in portfolio VAR in terms of money. (It should be noted that mathematically, VAR is a negative number, which actually decreases when the return increases.) Also, the curves on the graph get flatter, again as expected. This shows that each additional unit of VAR allowed, increases the portfolio Mean Return by less and less. Like the Standard Deviation, the VAR of revised portfolios for a given return is less than the VAR of the original portfolios, so the revised curve is shifted to the right. Also, the VAR of revised portfolios asymptotically converges to the VAR of the original portfolios for higher returns.

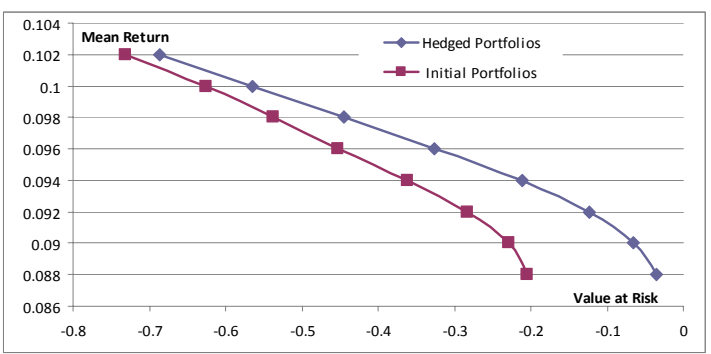

FIGURE II. PORTFOLIOS RETURN VERSUS VAR

\section{Portfolios Sharpe Ratio}

Figure 3 shows that the Sharpe Ratio of the revised portfolios is greater than the ratio of original portfolios, so the revised curve is shifted to the right. For example, a common goal in investments is to choose a portfolio that maximises the Sharpe Ratio.

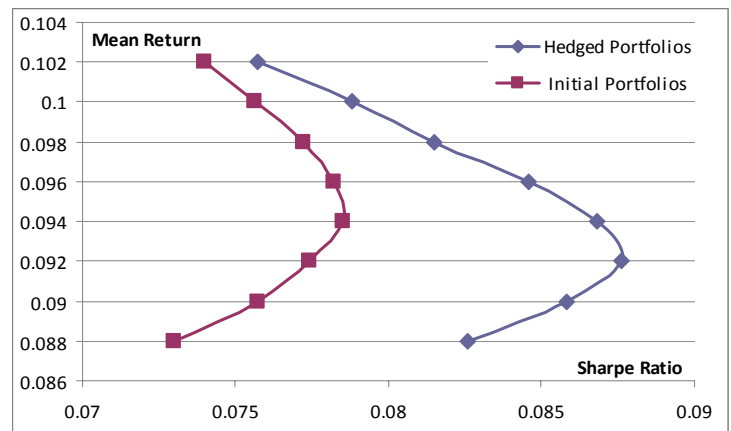

FIGURE III. SHARPE RATIO OF THE EFFICIENT PORTFOLIOS

From the graph it is possible to see that the revised portfolio with Mean Return of $9.2 \%$ and Sharpe Ratio of 0.088 (shown in Table 1 in red) is technically the best investment portfolio considering the Sharpe Ratio criteria. Therefore, this portfolio should be recommended to the Financial Executives.

\section{Portfolios Selection and Execution}

The selected and executed portfolio on the market is the revised portfolio with investments of $32.41 \%$ in Asset 1; $31.89 \%$ in Asset 3; and 36.7\% in Option 4; Mean Return $9.2 \%$; Sharpe Ratio, 0.088. It is recognised as technically the best portfolio based on the Maximal Sharpe Ratio criteria.

\section{E. Ongoing Portfolio Management: Performance Evaluation}

The Mean Return is simulated to stochastically measure the performance for the last six months and predict the annual return by using the data from November 2013 to April 2014. Stochastically calculated were the Variance, Standard Deviation, VAR, and Sharpe Ratio as well as the Six Sigma process capability metrics PNC. The executed portfolio has the following investment fractions: $32.41 \%$ in Asset $1 ; 31.89 \%$ in Asset 3; and $36.7 \%$ in Option 4, i.e. an option on Asset 4 applied to revise the initial portfolio. The expected range of return is $8.8 \%-10.2 \%$ and the target is $9.2 \%$. The simulation 
predicted annual values are: Mean Return, $8.78 \%$, which is missing the target range; Return Maximum, 169.58\%; Return Minimum, $-140.1 \%$ theoretically; Variance, 19.31\%; Standard Deviation, 43.95\%; VAR, -13.98\%; and Sharpe Ratio, 0.078. The probability is $39.1 \%$ that the return will be negative (i.e. loss); $44.4 \%$, within $0 \%-50 \%$; and $16.5 \%$, greater than $50 \%$. The probability is only $1.3 \%$ that the Mean Return will be within the target range. The predicted process metrics PNC is 0.987 , which is a very poor performance.

\section{F. Ongoing Portfolio Management: Portfolio Revision}

The stochastic optimisation model resolves the minimal mean-variance portfolio which gains $9.2 \%$. The investment fractions of revised portfolio with $9.2 \%$ return are: $37.81 \%$ in Asset 1; 25.69\% in Asset 3; and 36.5\% in Option 4. The predicted Mean Return is $9.2 \%$ with Variance, 20.21\%; Standard Deviation, 44.96\%; VAR, $-15.33 \%$; and Sharpe Ratio, 0.0855 . The probability that the portfolio return will be negative (i.e. loss) is $41.2 \%$; in the range $0 \%-50 \%, 42.5 \%$; and greater than $50 \%, 16.3 \%$. The Six Sigma PNC is 0.984 . This is a great improvement compared to original executed portfolio, bat with slightly higher risk.

\section{VERIFICATION OF METHOD RESUlts}

TABLE II. THE COMPARISON OF ACTUAL VS. PREDICTED RESULTS

\begin{tabular}{|c|r|r|r|r|}
\hline Result & Actual & Predicted & \multicolumn{1}{c|}{ Error } & Error \% \\
\hline $\boldsymbol{\mu}$ & 0.0878 & 0.0902 & 0.0273 & 2.73 \\
\hline VAR & -0.1398 & -0.1240 & -0.1130 & -11.30 \\
\hline SR & 0.0780 & 0.0880 & 0.1282 & 12.82 \\
\hline
\end{tabular}

The comparisons of the predicted versus actual results is presented in Table 2 showing the Mean Return $(\mu)$, VAR, and Sharpe Ratio (SR), and the associated absolute and percentage (\%) errors. For example, the Mean Return is overestimated by $2.73 \%$ which is a very good result. VAR is underestimated by $11.30 \%$ which is not a bad result at all. All in all, the results are reasonably good and acceptable. Therefore, the method results are successfully verified.

\section{CONCLUSION}

This method is generally applicable to Investment Management. The method can be specifically applied to ALM. In particular, from Solvency II perspectives, it proposes internal models options to (re)insurers, which can help them to reduce their capital requirements and VAR. The saved capital can be invested thus providing for higher business capabilities and increasing the competitive position, which is the ultimate objective. Considering the Bernstein statement "But the risk will always be there, so we must explore many interesting tools that can help us to control risks we cannot avoid taking" (Bernstein and Damodaran 1998), this method is just such a tool.

\section{ACKNOWLEDGMENT}

I would like to thank my daughter, Ivana Bubevska, for reviewing the paper and suggesting relevant improvements. She has also substantially helped with the editting and formatting of the paper. Her contribution has been essential for the successful publication of this work.

\section{REFERENCES}

[1] Adam, A., 2007. Handbook of Asset and Liability Management: From Models to Optimal Return Strategies, John Wiley \& Sons, 26 Oct 2007.

[2] Bernstein, P. L., and Damodaran, A., 1998. Investment Management, New York, John Wiley \& Sons, 1998.

[3] Bloomsbury, 2012. Asset Liability Management for Financial Institutions: Balancing Financial Stability with Strategic Objectives, Bloomsbury Information Ltd, 24 May 2012.

[4] Bourdeau, M., 2009. Market Risk Measurement Under Solvency II. In: Cruz, M., ed. The Solvency II Handbook, London, Risk Books - Incisive Media, 193-226.

[5] Cruz, M., 2009. The Solvency II Handbook, London, Risk Books Incisive Media.

[6] GDV, 2005. Discussion Paper for a Solvency II Compatible Standard Approach, Gesamtverband der Deutschen Versicherungswirtschaft. Available from: http://www.gdv.de/Downloads/English/Documentation_Sol_II.pdf [Accessed 20 June 2011]

[7] Glasserman, P., 2004. Monte Carlo Methods in Financial Engineering, New York, Springer Science.

[8] Hayler, R., Nichols, M. D., 2006. Six Sigma for Financial Services: How Leading Companies Are Driving Results Using Lean, Six Sigma, and Process Management, McGraw-Hill, October 26, 2006.

[9] Jorion, P., 2011. Financial Risk Manager Handbook, New Jersey, John Wiley \& Sons.

[10] Macaulay, F. R., 1938. "Some Theoretical Problems Suggested by the Movments of Interest Rates", National Bureau of Economic Research, Ney York, 1938.

[11] Maginn, J.P., et al., 2007. Managing Investment Portfolios: A Dynamic Process, $3^{\text {rd }}$ ed., - (CFA Institute investment series), New Jersey, John Wiley \& Sons, 2007.

[12] Markowitz, H.M., 1952. "Portfolio Selection", The Journal of Finance, Vol. 7, pp. 77-91, 1952.

[13] Markowitz, H.M., 1987. Mean-Variance Analysis in Portfolio Choice and Capital Markets, Oxford, UK, Basil Blackwell.

[14] Mitra, G., Schwaiger, K., 2011. Asset and Liability Management Handbook, Palgrave Macmillan, 29 Mar 2011.

[15] Redington, F. M., 1952. "Review of the Principles of Life Office Valuations", Journal of the Institute of Actuaries, Vol.78, part. 3, No 350, pp. 286-340, 1952.

[16] Siviy, J. M., Penn, L. M., and Stoddard, R. W., 2007. CMMI® and Six Sigma: Partners in Process Improvement (SEI Series in Software Engineering), Addison-Wesley Professional, December 28, 2007.

[17] SST, 2004. White Paper of the Swiss Solvency Test, Swiss Federal Office of Private Insurance. Available from: http://www.naic.org/documents/committees_smi_int_solvency_switzerla nd_sst_wp.pdf [Accessed 20 June 2011]

[18] Stamatis, D. H., 2003. Six Sigma for Financial Professionals, Wiley, September 2003 .

[19] Tarantino, A., Cernauskas, D., 2009. Risk Management in Finance: Six Sigma and Other Next-Generation Techniques, Wiley, May 4, 2009

[20] Ziemba, W. T. and Vickson, S. W., ed., 2006. Stochastic Optimization Models in Finance, World Scientific, 2006. 